\title{
Ratio between Heat and Mass Transfer when Concentrating the Solution in a Cooling Tower
}

\author{
Musii Tseitlin $^{1}$, Valentina Raiko ${ }^{2}$ \\ 1. Department of Chemical Engineering and Environment Protection, National Technical University "Kharkiv \\ Polytechnic Institute”, UKRAINE, Kharkiv, Kirpichova, 2, E-mail: michelzeitlin@gmail.com \\ 2. Department of Labor and Environment Protection, National Technical University "Kharkiv Polytechnic \\ Instutute”, UKRAINE, Kharkiv, Kirpichova, 2, E-mail: raiko.hpi@gmail.com
}

\begin{abstract}
The ratio between the intensity of the mass transfer in gas and the heat transfer in liquid during the evaporative solution concentration has been studied. It was determined that the share of liquid resistance in the total resistance to enthalpy transfer increases in the temperature range from 30 to $50{ }^{\circ} \mathrm{C}$ by almost 2 times, and reaches $40 \%$. The technique has been developed for the separate determination of the mass transfer coefficients in gas and heat transfer in liquid.
\end{abstract}

Keywords - concentrating solution, cooling tower, mass transfer, heat transfer, resistance to enthalpy transfer, step phase contact, fall-through trays.

\section{Introduction}

Cooling towers, originally designed for concentrating solutions containing sodium chloride, are now used almost exclusively for evaporative water cooling in industrial water circulation systems. The negative effects of such systems on the environment are due to the need for temporary or continuous replacement of high salinity water for fresh. This disadvantage can be turned into advantage by returning to the original purpose of the cooling towers and using technological solutions that need to be concentrated for apparatuses cooling.

Evaporative liquid cooling during its direct contact with air is due to the complex combination of heat and mass exchange. This study is devoted to identifying the ratio between the rates of these processes and identifying the stages that determine the kinetics of solution concentration. For evaporative cooling and solution concentration, a cooling tower [1] with a step phase contact, equipped with fall-through trays with large free cross section and large (50$100 \mathrm{~mm}$ ) holes, is to be concerned. The research was conducted in relation to the mentioned apparatus design.

\section{Literature Review}

In the theory of evaporative cooling [2], "dry" and "wet" heat exchange are distinguished. The former is due to the temperature difference of the contacting phases, the latter is due to the thermal effect of water evaporation or condensation. Both of them are closely related, which complicates the calculation for the cooling tower using the traditional equations of heat and mass exchange. To simplify the calculations, it was proposed (see, for example, [3]) to consider heat transfer due to both mechanisms, as a whole process, the driving force of which is the difference between the actual specific air enthalpy in contact with the cooling liquid, and air in equilibrium with this liquid. In this case, the kinetics of heat transfer between the contacting phases is described by the following equation:

$$
G \frac{\mathrm{d} H_{g}}{\mathrm{~d} S}=k_{H}\left(H_{g}-H^{*}\right)
$$

where $G$ is the mass air flow, $\mathrm{kg} / \mathrm{s} ; H_{\mathrm{g}}$ and $H^{*}$ are the air enthalpy in contact with the cooling liquid and the air in equilibrium with this liquid, respectively, $\mathrm{kJ} / \mathrm{kg}$ of dry air; $S$ is phase contact surface, $\mathrm{m}^{2} ; k_{H}$ is enthalpy transfer coefficient, $\mathrm{kg} / \mathrm{m}^{2} \mathrm{~s}$. 
The enthalpy coefficient $k_{H}$ is determined with the following formula:

$$
\frac{1}{k_{H}}=\frac{1}{k_{g}}+\frac{H^{*}-H_{i}}{\alpha_{l}\left(t_{i}-t_{l}\right)}
$$

where $k_{g}$ is the mass transfer coefficient in gas, $\mathrm{kg} / \mathrm{m}^{2} \mathrm{~s} ; \alpha_{l}$ is heat transfer coefficient of the liquid, $\mathrm{W} / \mathrm{m}^{2}$-degrees; $t_{i}, t_{l}$ are surface temperatures of the gas and liquid interface and the main mass of the liquid, respectively, ${ }^{\circ} \mathrm{C}, H_{i}$ is the air enthalpy in equilibrium with the solution at temperature $t_{i}$.

According to equation (2), the total resistance to enthalpy transfer is the sum of two terms, the former determining the resistance in the gas, and the latte determining the resistance in the liquid phase. The studies of nozzles for traditional cooling towers [4] show that resistance of liquid is from 27 to $46 \%$ of the total resistance to enthalpy transfer. Data on similar studies performed for fall-through trays are missing.

\section{Research methodology}

The experimental study of the evaporative solution concentration using the fall-through trays was carried out at a set that included an experimental apparatus, a set of auxiliary equipment and a set of measuring instruments. The experimental apparatus consisted of a base with built-in pipelines for air supply and drainage of the solution, three shells installed on it with a diameter and height of $0.5 \mathrm{~m}$, and a lid equipped with a pipeline for air outlet and a device for distributing the solution entering the apparatus. The trays to be examined were mounted between the side-bars, i.e. disks punched with 25 holes $65 \mathrm{~mm}$ in diameter evenly distributed over the square. The free section of the trays was $42 \%$. The salt solution (brine) with a mass fraction of $\mathrm{NaCl} 24-25 \%$ was subjected to concentration in the set.

\section{Research results}

In order to make sure that there is a significant resistance to enthalpy transfer of the liquid, a series of experiments was performed in which the temperature of the initial brine varied within 35-70 ${ }^{\circ} \mathrm{C}$. The results are presented in Fig. 1 as the dependence of the enthalpy transfer coefficient on the average temperature of the liquid in the apparatus.

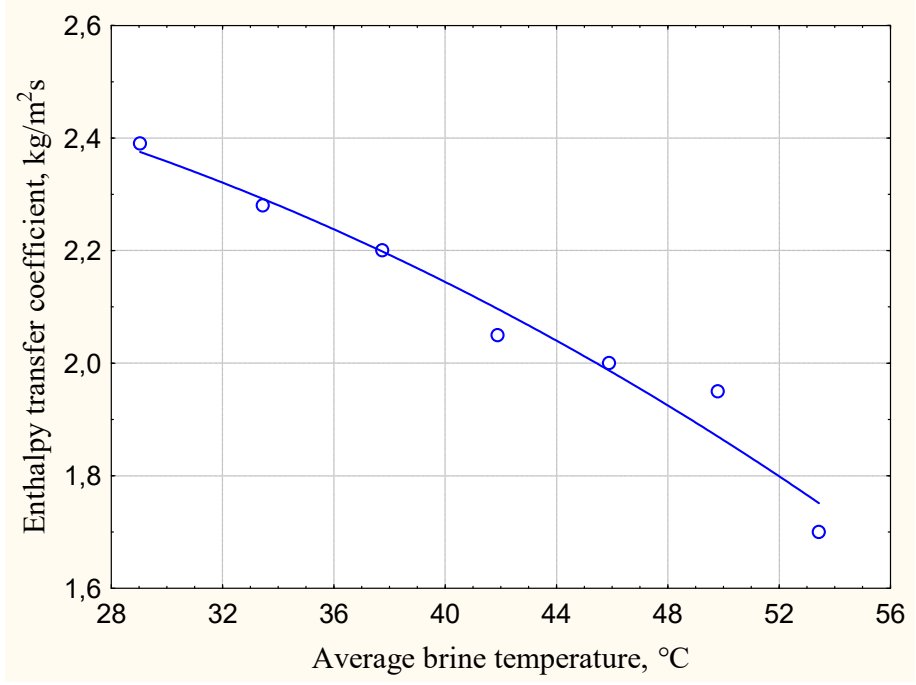

Fig. 1. Dependence of enthalpy transfer coefficients on temperature 
As it can be seen from the graph, when the temperature increases from 29 to $53{ }^{\circ} \mathrm{C}$, the value of $k_{H}$ falls by more than a third and with an increase in temperature, the tendency for $k_{H}$ falling increases. Such a strong influence of temperature on the enthalpy transfer coefficient can be explained by analyzing equation (2).

As it is well known, temperature has little effect on the mass transfer coefficients in gas, $k_{\mathrm{g}}$, and heat transfer in liquid $\alpha$ [3]. At the same time, the factor of the term $\left(H^{*}-H_{\mathrm{i}}\right) /\left(t_{\mathrm{i}}-t_{1}\right)$, which determines the resistance to enthalpy transfer of the liquid, is rather dependent on temperature.

This allows concluding that a significant effect of temperature on the enthalpy transfer coefficient is due to the fact that the resistance to enthalpy transfer of the liquid constitutes a significant fraction of the total resistance.

Next, the technique for the separate determination of mass transfer coefficients in gas and heat transfer in liquid was developed in order to determine the effect of temperature on the fraction of resistance to enthalpy transfer concentrated in the liquid.

The idea of the technique is based on the fact that having conducted several experiments with the same air and brine flow rates (i.e. with constant $k_{\mathrm{g}}$ and $\alpha$ ), but different temperatures and finding the ratio $\left(H^{*}-H_{\mathrm{i}}\right) /\left(t_{1}-t_{\mathrm{i}}\right)$, it is possible to calculate the mass transfer coefficients in gas and heat transfer in the liquid separately. It was also assumed that, $\left(H^{*}-H_{i}\right) /\left(t_{l}-t_{i}\right) \approx(\mathrm{d} H / \mathrm{d} t)_{t=t_{o c}}$ where $H$ is the air enthalpy that is in equilibrium with the brine at temperature $t$.

We performed calculations of the air enthalpy in equilibrium with a saturated sodium chloride solution at different temperatures of the brine, and then the temperature derivative of enthalpy. The results of these calculations are summarized as the following equation:

$$
\mathrm{d} H / \mathrm{d} t=0,7+0,0144 t+0,00036 \mathrm{t}^{2},
$$

The heat transfer coefficient in the liquid and the mass transfer in the air were determined as follows. According to the results of experiments carried out at different temperatures, using the method of regression analysis the values of the coefficients $a_{0}$ and $a_{1}$ in the linear equation were found

$$
1 / \mathrm{k}_{H}=\mathrm{a}_{0}+\mathrm{a}_{l}(d \mathrm{H} / d \mathrm{t}),
$$

Comparing equations (4) and (2) and, taking into account the accepted assumption, one can see that $a_{0}=1 / k_{\mathrm{g}}$, and $a_{1}=1 / \alpha$. This allows finding the needed values of heat transfer coefficients in liquid $\alpha$ and mass transfer coefficient in gas $k_{\mathrm{g}}$.

Results of the experiments processed showed that the proportion of liquid resistance in the total resistance to enthalpy transfer in the temperature range studied varies from $18 \%$ at $29{ }^{\circ} \mathrm{C}$ to $40 \%$ at $53{ }^{\circ} \mathrm{C}$.

The represented data shows that the resistance to heat transfer of the liquid in the process of evaporative solution concentration when using in the cooling tower of fall-through trays is as large as when using conventional irrigators. This indicates that an attempt to intensify cooling only by increasing the mass transfer coefficient in the gas, for example, by increasing the air rate, will not have large effect, especially at high temperatures of the cooling solution. The result can be achieved only with simultaneous turbulization of both gas and liquid phase.

The technique of separate determination of the coefficients $k_{\mathrm{g}}$ and $\alpha$ allows studying the influence of the main factors of the enthalpy transfer process on each of these coefficients 
separately. In particular, to calculate the dependences of these kinetic coefficients on the gas rate in the total cross section of the apparatus $w(\mathrm{~m} / \mathrm{s})$ and the irrigation density $l\left(\mathrm{~m}^{3} / \mathrm{m}^{2} \mathrm{~s}\right)$, the following equations were obtained.

$$
\begin{aligned}
& k_{\mathrm{g}}=0,82 w^{0,88} l^{0,85} ; \\
& \alpha=17,8 w^{0,54} l^{0,47}
\end{aligned}
$$

Equations (5), (6) indicate that the gas rate and irrigation density are approximately equal to both the mass transfer rate in the gas and the heat transfer rate in the liquid.

\section{Conclusions}

The ratio between the intensity of the mass transfer in gas and the heat transfer in liquid during the evaporative solution concentration in direct contact with air has been studied. It was determined that the share of liquid resistance in the total resistance to enthalpy transfer increases with temperature, increasing in the range from 30 to $50{ }^{\circ} \mathrm{C}$ by almost 2 times, and reaches $40 \%$.

The technique has been developed for the separate determination of the mass transfer coefficients in gas and heat transfer in liquid, which makes it possible to study the influence of the main factors of the enthalpy transfer process on each of these coefficients separately. In particular, equations are given for estimating gas rate and irrigation density that impact coefficients mentioned.

The results obtained may be interesting both from the viewpoint of studying the mechanism of enthalpy transfer process and for developing a method for calculating the apparatus for the evaporative solution concentration.

\section{References}

[1] V. P. Kichanov, A. M. Sukhanov, E. G. Shterle, V.D. Smolyak, T.N. Luk'yanenko, Yu. N. Skrynnik, “Gradirnya,” USSR, A.s. 1281860, Jan. B.I. № 1, 1987.

[2] V. S. Galustov, "Teplomassoobmennyye protsessy i apparaty s neposredstvennym kontaktom faz v teploenergetike," Energiya i menedzhment, no. 4, July August, pp. 17-19, 2003..

[3] T. Shervud, R. Pigford and Ch.Uilki, Massoperedacha, M.: Khimiya, 1982.

[4] W. H. Mc'Adams, J. B. Pohlens and R. C. John, 'Transfer of heat and mass between air and water' Chem. Eng. Progr, vol. 45, pp. 241-259, 1949 